\title{
THE PRACTICE AND DRIVERS OF CSR DISCLOSURE AMONG THE BLUE-CHIP COMPANIES IN NORTH MACEDONIA
}

\author{
Todor Tocev \\ Faculty of Economics-Skopje, Ss Cyril and Methodius University \\ todor.tocev@eccf.ukim.edu.mk \\ Ivan Dionisijev \\ Faculty of Economics-Skopje, Ss Cyril and Methodius University \\ ivan.d@eccf.ukim.edu.mk \\ Zoran Minovski \\ Faculty of Economics-Skopje, Ss Cyril and Methodius University \\ zoran.minovski@eccf.ukim.edu.mk
}

\begin{abstract}
Non-financial reporting is becoming an increasingly common topic of discussion and is a matter of time before it is regularly implemented around the world. Stakeholders want to see how companies contribute to the common good and what social activities they undertake, so although in the Macedonian practice Corporate Social Responsibility (CSR) disclosure is not mandatory, there is a growing intention to publicly disclose information about social activities. CSR is extremely important for businesses and other stakeholders, and it requires businesses to develop a corporate strategy that balances environmental, social, and ethical concerns. Through this type of activities, companies manage to increase their influence in society, to leave a good impression but also to contribute to the improvement of society and place of living, which is a win-win situation for everyone.

The paper aims to examine the level of CSR reporting in domestic practice, through research conducted on the blue-chip companies listed on the Macedonian Stock Exchange. We analyzed the financial and annual reports and official websites of the joint stock companies that were part of the MBIIO index in the period from 2016 to 2020. First, a theoretical review of the CSR is presented, followed by a literature review on the CSR's indicators and the state of the CSR in the Macedonian practice. Our findings from the conducted content analysis and linear regression show that larger and more profitable companies show a greater propensity for social responsibility and display more information about their undertaken social related activities.
\end{abstract}

Keywords: CSR, non-financial disclosure, North Macedonia

JEL Classification: $M 14$, M40

http://hdl.handle.net/20.500.12188/15915

http://doi.org/10.47063/EBTSF.2021.0002 